\title{
Uma Possível Associação entre Ciência e Tecnologia no Ensino de Ciências: o exemplo do telefone
}

André Coelho da Silva

\begin{abstract}
Resumo
Neste trabalho, num primeiro momento, são discutidas a tecnologia, a ciência e algumas das formas como suas possíveis inter-relações são encaradas. Num segundo momento, são apresentados resultados de uma revisão bibliográfica onde foram buscados artigos científicos da área de ensino de ciências que procuram relacionar algum conteúdo da ciência a aspectos de artefatos tecnológicos contemporâneos. Por fim, num terceiro momento, tendo notado certa carência de trabalhos dessa natureza voltados explicitamente para fins didáticos, é apresentada uma sequência de ensino que procura discutir elementos associados ao surgimento, ao desenvolvimento e ao funcionamento do telefone. Como parte integrante dessa sequência, sugere-se também a realização de um experimento relativamente simples.

Palavras-chave: artefato tecnológico, telefone, tecnologia, revisão bibliográfica.

Abstract

In this paper, at first, technology, science and some of the ways their possible interrelations are seen are discussed. Secondly, are presented the results of a literature review in which were sought scientific papers of the area of science education that seek to relate some science content to aspects of contemporary technological artifacts. Finally, on a third moment, having noticed a certain lack of studies of this nature directed explicitly to education, is presented a teaching sequence that discusses elements related to the emergence, development and operation of the telephone. As part of this sequence, it is suggested performing a relatively simple experiment.
\end{abstract} review.

Key words: technological artifact, telephone, technology, literature 


\section{Introdução}

Muitos estudos indicam que, em geral, não há compatibilidade entre os assuntos que interessam os estudantes e os conteúdos presentes nos currículos das disciplinas científicas - o que certamente contribui para o baixo nível de participação dos estudantes nas atividades sugeridas e para o consequente aborrecimento por parte dos professores.

Mas quais são mesmo os assuntos que interessam crianças e adolescentes para a aprendizagem das ciências naturais?

Duas pesquisas relativamente recentes (Baram-Tsabari e Yarden, 2005; e Christidou, 2006) indicam que um dos assuntos que mais parece despertar esse interesse em crianças e adolescentes é a tecnologia. Uma das possíveis hipóteses para explicar esse resultado é o fato de que elementos da tecnologia se fazem presentes em nosso dia-a-dia, no mundo material. E como nos lembram Dias, Barlette e Martins (2009), os alunos valorizam a aplicabilidade do que estudam na escola em seu dia-a-dia, isto é, muitas vezes eles desejam que a importância ou utilidade de estudar determinados conteúdos Ihes seja explicitada.

Embora a relação de muitos estudantes com o conhecimento possa ser predominantemente "utilitarista", discutir em sala de aula as possíveis relações entre ciência e tecnologia pode ir muito além da satisfação desse aspecto, favorecendo a compreensão da ciência e da tecnologia como elementos socioculturais e contribuindo para a desmitificação da tecnologia como pura e simples aplicação da ciência. Além disso, vale lembrar ainda que os Parâmetros Curriculares Nacionais para o Ensino Médio (Brasil, 1997) também dão bastante destaque à tecnologia ${ }^{1}$.

Uma das formas de explicitar as relações entre ciência e tecnologia é discutir o processo de surgimento, desenvolvimento e funcionamento de artefatos tecnológicos, afinal, como nos lembra Granger (1994), a penetração cotidiana da ciência em nossas sociedades se manifesta especialmente por utilizarmos objetos impregnados de pensamento científico.

Tendo em vista essas breves considerações, este trabalho está estruturado da seguinte maneira: primeiramente, apresento uma discussão acerca da tecnologia e suas possíveis interrelações com a ciência; num segundo momento, apresento os resultados de uma revisão de literatura onde foram buscados trabalhos da área de ensino de ciências que procuram relacionar conteúdos científicos a aspectos de alguns artefatos tecnológicos contemporâneos; e, finalmente, num terceiro momento, apresento uma sequência de ensino que procura discutir o surgimento, o desenvolvimento e o funcionamento do telefone. Ressalto ainda que, como parte integrante da

\footnotetext{
${ }^{1}$ Os Parâmetros Curriculares Nacionais para o Ensino Médio são divididos em quatro partes: Bases Legais; Linguagens, Códigos e suas Tecnologias; Ciências da Natureza, Matemática e suas Tecnologias; e Ciências Humanas e suas Tecnologias. Ou seja, já nos títulos é dado bastante destaque à tecnologia.
}

R. B. E. C. T., vol 6, núm. 3, set-dez.2013 ISSN - 1982-873X 
sequência de ensino, sugiro e detalho um experimento pensado na perspectiva de favorecer o entendimento de elementos associados a esse artefato tecnológico.

\section{A tecnologia: uma aplicação da ciência?}

Gardner (1999) afirma que o termo "tecnologia" pode estar associado a uma ampla gama de significados:

"[...] Tecnologia pode se referir a artefatos ('a impressora a laser é uma bela peça de tecnologia'), processos ('agora temos a tecnologia para gerar eletricidade a partir de resíduos'), sistemas sociais ('os EUA e o Japão lideram o mundo em tecnologia'), campos de trabalho ('Pat quer trabalhar com tecnologia'), ou campos de estudo ('Mumford foi um escritor no início da história da tecnologia'). Ciência, também é um termo amplo, pode significar conhecimento organizado sobre fenômenos naturais ('a teoria da relatividade de Einstein foi uma grande contribuição para a ciência'), os processos de pensamento que geram esse conhecimento ('descoberta da estrutura do DNA foi um triunfo da ciência moderna'), ou como uma rubrica para um conjunto de disciplinas ('A Psicologia enquanto ciência tem um século de idade'), mas também pode se referir a sistemas sociais e campos de trabalho e estudo. Os termos são usados de forma diferente por vários autores, em várias culturas, $e$ em vários momentos históricos. [...]" p. 331 - Tradução do original feita pelo autor deste trabalho.

Além disso, Daumas (1976) apud Gardner (1999) nos lembra que os significados associados à palavra "tecnologia" também dependem da língua. Em inglês, por exemplo, a palavra "technology" englobaria significados que em francês seriam designados por duas palavras: "technique" (conhecimento organizado e habilidade) e "technologie" (tecnologia científica).

A tecnologia tem como proposta, segundo Gardner (1999), projetar, criar e melhorar artefatos, materiais, sistemas e procedimentos com o intuito de atender as necessidades e os desejos humanos. Com isso o autor a difere da ciência, a qual teria como propósito o conhecimento teórico de determinado assunto. Apesar dessa diferença de propósitos, a partir da Revolução Industrial - iniciada no Reino Unido em meados do século XVIII -, os métodos de pesquisa adotados pelos tecnólogos teriam se aproximado dos métodos adotados pelos cientistas.

Gardner (1999) distingue ainda quatro visões a respeito da relação entre ciência e tecnologia: a idealista, a demarcacionista, a materialista e a interacionista. 
A visão idealista vê a tecnologia como uma mera aplicação da ciência (crença culturalmente dominante). Assim, as leis e teorias científicas seriam a base para o surgimento de novos produtos tecnológicos. Embora os defensores dessa postura deem diversos exemplos provenientes da história da ciência (a descoberta dos raios $X$ resultando nos aparelhos para diagnósticos médicos ou os experimentos ópticos de Bacon resultando nos óculos, por exemplo), Gardner (1999) ressalta a complexidade envolvida na transição do desenvolvimento científico para o desenvolvimento tecnológico, isto é, muitas das características de determinado artefato tecnológico não seriam dedutíveis de princípios científicos, mas sim, requereriam o trabalho de engenheiros habilidosos.

A visão demarcacionista, tendo como base a ideia de que a ciência e a tecnologia possuem objetivos distintos, considera esses campos como totalmente separados. Os defensores dessa postura nos lembram que muitos artefatos - como facas de pedra, garrafas de vidro e pontes, por exemplo - foram desenvolvidos sem qualquer consulta a pesquisas científicas. Outro fato que também poderia justificar essa visão é o de que muitos artefatos tecnológicos foram desenvolvidos tendo como base a crença em princípios científicos que hoje são considerados equivocados (GARDNER, 1999).

A visão materialista vê a tecnologia como precursora da ciência. Nesse sentido, a experiência humana com ferramentas, máquinas, instrumentos de medida e outros artefatos seria necessária para o desenvolvimento conceitual. Relógios mais precisos, por exemplo, não só permitiriam melhores medidas do tempo, mas também induziriam novas e diferentes formas de conceber o mundo.

A visão interacionista vê ciência e tecnologia trabalhando e aprendendo uma com a outra. Assim, tanto a pesquisa científica poderia auxiliar no desenvolvimento de novas tecnologias, quanto os problemas tecnológicos poderiam estimular novas pesquisas científicas. A complexa história do desenvolvimento e melhoria da máquina de vapor e o desenvolvimento do desfibrilador seriam bons exemplos a respaldar essa postura. Gardner (1999) destaca ainda que a interação entre cientistas e tecnólogos foi potencializada a partir do investimento em pesquisa por parte das indústrias.

Essas quatro visões podem se servir de exemplos da história da ciência e da tecnologia como justificativa, logo, sozinha nenhuma daria conta de explicar todos os casos. Além disso, o autor frisa ainda que não se trata de visões nitidamente distintas, sendo possível que mais de uma dê conta de explicar o desenvolvimento de um determinado artefato.

Por fim, gostaria de destacar que à complexidade dessa discussão acerca das possíveis relações entre ciência e tecnologia está também associada a discussão acerca do que é, ou do que pode ser considerado um artefato tecnológico.

Segundo Cupani (2004) um artefato é algo produzido, algo artificial: 
"[...] $O$ artefato não precisa ser todavia uma coisa (por exemplo, uma bicicleta, ou um remédio), podendo tratar-se também da modificação do estado de um sistema natural (por exemplo, desviar ou represar o curso de um rio), ou bem da transformação de um sistema (por exemplo, ensinar alguém a ler). [...]" p. 495.

Outro ponto um tanto quanto nebuloso esclarecido por Cupani (2004) é a distinção entre técnica e tecnologia. Segundo o autor, a técnica consiste na capacidade humana de modificar deliberadamente materiais, objetos e eventos. A tecnologia, por sua vez - embora relacionada à técnica -, teria como característica adicional certa associação à ciência experimental.

\section{A tecnologia no ensino de ciências: reflexões e propostas}

Poduska e Lunetta (1984) procuraram discutir como os currículos e alguns projetos para o ensino de física estadunidenses abarcaram a tecnologia na segunda metade do século XX. Segundo os autores, a partir de meados da década de 50 esses currículos eram criticados por incluir aspectos da tecnologia. Provavelmente por influência dessas críticas, já na década de 60 os currículos teriam eliminado as referências a aplicações tecnológicas. E mesmo antes, nos textos de 1956 do PSSC (Physics Science Study Committee), as referências a dispositivos práticos seriam mínimas. No que diz respeito ao projeto Harvard (décadas de 70 e 80), que visava apresentar a física no contexto da história, cultura e sociedade, Poduska e Lunetta (1984) afirmam que ele também teria dado pouca ênfase a esse aspecto. Entretanto, ainda segundo os autores, no início da década de 80 teria havido um ressurgimento do interesse em apresentar a física fazendo-se referência a elementos da tecnologia.

Esse ressurgimento pode ser reflexo do fortalecimento do chamado movimento CTS (Ciência, Tecnologia e Sociedade), o qual propõe para o ensino de ciências:

"[...] uma nova estruturação de conteúdos e procedimentos de ensino. Isso ocorre com base em orientações curriculares que incluam questões tecnológicas e sociais, além dos conceitos científicos e estratégias de ensino que busquem promover uma aprendizagem ampla de conceitos científicos aliada à construção de uma postura cidadã." (FIRME e AMARAL, 2008, p. 252253).

Com isso, espera-se formar pessoas capacitadas a participarem de forma crítica e consciente no processo de tomada de decisões e nos debates sociais, pessoas preocupadas com as implicações sociais inerentes ao desenvolvimento de inovações científicas e tecnológicas (SILVEIRA e BAZZO, 2009; PINHEIRO, SILVEIRA e BAZZO, 2007). 
Mais especificamente em relação à discussão de aspectos associados a artefatos tecnológicos no ensino de física, Utges, Fernández e Jardón (1996) sugerem que essa abordagem pode auxiliar os estudantes a compreenderem que a física não diz respeito apenas ao abstrato. Além disso, isso poderia propiciar a integração entre os conhecimentos científico e tecnológico, favorecendo o reconhecimento das inter-relações entre Ciência, Tecnologia e Sociedade.

Já segundo Angotti, Bastos e Mion (2001) é preciso superar a ideia de que nossas relações com os artefatos tecnológicos são demasiadamente óbvias para merecerem discussão. Nesse sentido, os autores sugerem a importância de questionarmos e refletirmos acerca da fabricação, do funcionamento e das causas e consequências da inserção desses artefatos em nossa sociedade, o que poderia contribuir para a conscientização de educandos e educadores. Em outro trabalho, Angotti e Mion (2001) afirmam ainda que uma proposta de ensino focada na discussão de "como funcionam" artefatos tecnológicos enquanto construções humanas pode auxiliar na construção da cidadania.

A fim de verificar a existência de trabalhos que sugerem sequências de ensino que relacionem a ciência a alguns artefatos tecnológicos contemporâneos, realizei uma busca por artigos científicos nos seguintes periódicos da área de ensino de ciências: A Física na Escola (Brasil), Alexandria: Revista de Educação em Ciência e Tecnologia (Brasil), Caderno Brasileiro de Ensino de Física (Brasil), Ciência \& Educação (Brasil), Ciência \& Ensino (Brasil), Ciência em Tela (Brasil), Ensaio: Pesquisa em Educação em Ciências (Brasil), Experiências em Ensino de Ciências (Brasil), Investigações em Ensino de Ciências (Brasil), Revista Brasileira de Ensino de Ciência e Tecnologia (Brasil), Revista Brasileira de Ensino de Física (Brasil), Revista Brasileira de Pesquisa em Educação em Ciências (Brasil), International Journal of Science Education (Reino Unido), Physics Education (Reino Unido), Research in Science \& Technological Education (Reino Unido), Revista Electrónica de Enseñanza de las Ciencias (Espanha), Revista Electrónica de Investigación en Educación en Ciencias (Argentina) e Science \& Education (EUA). A busca foi realizada desde a primeira edição de cada periódico até as edições publicadas antes de junho de 2013.

Inicialmente utilizei para a busca o termo "artefato". Contudo, notei que alguns artigos relevantes para a busca não estavam sendo contemplados. Optei, então, por modificar o critério da busca, passando a utilizar como termos os seguintes artefatos tecnológicos contemporâneos: CD/DVD, controle remoto, aparelho de ressonância magnética, telefone, laser (seu funcionamento e não artigos que o utilizam em atividades práticas), computador (incluindo seus componentes), microfone, geladeira, ar condicionado, televisão, rádio, alarme, aparelho de som, aparelho de raios $\mathrm{X}$, aparelho de ultrassom, câmera (filmadora ou fotográfica), impressora, microondas e mostradores de cristal líquido (LCD). Justifico a escolha por esses artefatos tecnológicos por acreditar que são contemporâneos e que seus funcionamentos estão relacionados a conceitos científicos. Vale ressaltar, contudo, que por se tratarem de critérios de busca pouco objetivos, 
provavelmente há artefatos tecnológicos contemporâneos que poderiam fazer parte dessa lista, mas que não o fizeram.

A partir dessa busca foram encontrados 47 artigos $^{1}$ que discutiam aspectos relacionados ao funcionamento de algum dos artefatos tecnológicos supracitados. Entretanto, em apenas 15 (32\%) desses trabalhos seus autores sugerem explicitamente a possibilidade de que o assunto seja discutido no ensino básico de física (trata-se dos artigos apresentados em negrito na nota de rodapé número 2 ).

Analisando os trabalhos selecionados, foi possível verificar que oito abordam aspectos associados ao funcionamento do aparelho de ultrassom, sete ao funcionamento do laser, seis ao funcionamento do aparelho de raios $X$, seis ao funcionamento do aparelho de micro-ondas, cinco ao funcionamento dos LCDs, cinco ao funcionamento do aparelho de ressonância magnética, quatro ao funcionamento do telefone, três ao funcionamento do $C D$, três ao funcionamento da televisão, dois ao funcionamento do computador, dois ao funcionamento do rádio, um ao funcionamento das câmeras e um ao funcionamento do DVD (frisando que um mesmo trabalho pode ter abordado mais de um artefato).

Outro dado interessante é o de que foram encontrados artigos em apenas cinco dos 18 periódicos buscados: 35 artigos foram encontrados no "Physics Education", seis na revista "A Física na Escola", quatro no "Caderno Brasileiro de Ensino de Física", um na "Ciência \& Ensino" e um na "Experiências em Ensino de Ciências".

Quanto à data de publicação dos artigos selecionados, o mais antigo é de 1968 e os mais recentes de 2012. Além disso, 22 dos 47 trabalhos (47\%) foram publicados no século XXI, o que pode sugerir certa tendência de aumento no número de pesquisas voltadas para o estudo de inter-relações entre tópicos científicos e artefatos tecnológicos. Há que se lembrar, todavia, que a busca contemplou apenas artefatos tecnológicos contemporâneos e não quaisquer artefatos tecnológicos - o que também pode ajudar a explicar a observação dessa tendência.

Tendo em vista as limitações de espaço e o fato de que na próxima seção deste trabalho apresento uma sequência de ensino que procura discutir elementos relacionados ao surgimento, ao desenvolvimento e ao funcionamento do telefone, procuro agora discutir de maneira sucinta

\footnotetext{
${ }^{1}$ Abdul-Razzak, Bushey e Winn (2011); Andrews (2000); Andrews, Simmons e Williams (1996); Babichak (1998); Bagnato (2001); Ball (1980); Barker (1996); Bilaniuk e Bilaniuk (1984); Bradshaw (1983); Bryant (1978); Cammarata e Wautelet (1999); Catelli e Villas-Boas (2011); Cavalcante, Peçanha e Leite (2011); Cavalcante, Peçanha e Leite (2012); Costa (2007); Crawford e Ondris-Crawford (1994); Damasio e Calloni (2008); Ellington, Addinall e Hately (1980); Ericson (1972); Fox (1996); Freeman (1970); French (2011); Gosling (1989); Hare (2010); Heavens (1968); Hessenbruch (1995); Hill (1978); Hill (1989); Hughes (2001); Kawalec (2012); Keevil (2001); Laburú et al. (2000); Laburú, Simõe e Urbano (1998); Menezes (2005); Michael (2001); Mion, Alves e Carvalho (2009); Orton (1987); Parker e Vollmer (2004); Pullan (1978); Starrett (2008); Straulino e Orlando (2012); Sumner (1995); Valadares e Moreira (1998); Vollmer (2004); Vollmer e Möllmann (2011); Vollmer, Möllmann e Karstädt (2004a); Vollmer, Möllmann e Karstädt (2004b).
} 
considerações apresentadas pelos autores dos quatro trabalhos que abordaram aspectos associados a esse artefato tecnológico.

Menezes (2005) procurou evidenciar como conhecimentos da física podem propiciar a compreensão de acontecimentos e situações de nosso dia-a-dia. Atentando para sua mesa de trabalho, o autor discute sucintamente aspectos associados ao funcionamento de alguns artefatos ali presentes. Sobre o telefone, mais especificamente o telefone celular, Menezes (2005) comenta a respeito da produção, da conversão e da transmissão do sinal.

Já Hare (2010) sugere um experimento de baixo custo capaz de converter a energia transportada pelas ondas de um telefone celular em energia elétrica - a qual é, então, utilizada para acender uma lâmpada LED. Além de discutir elementos associados ao experimento proposto, o autor também tece comentários a respeito de ondas eletromagnéticas, das antenas transmissoras/receptoras de sinais e das redes utilizadas pelas operadoras de telefonia móvel.

French (2011) discute a teoria envolvida no chamado fenômeno da "gaiola de Faraday" e sugere algumas demonstrações experimentais que podem ser utilizadas para bloquear o sinal de telefones celulares. Embora a abordagem teórica apresentada pelo autor envolva um formalismo matemático relativamente sofisticado, as demonstrações sugeridas são de fácil realização e envolvem materiais de baixo custo.

Kawalec (2012) também procurou discutir elementos associados ao funcionamento da telefonia móvel, mais especificamente, a produção e a transmissão de sinais e o sistema global para comunicações móveis (o "GSM" - global system for mobile communications) - o qual seria o sistema mais popular em termos de telefonia móvel. O foco das análises realizadas pelo autor recai nos problemas relacionados aos telefones celulares como consequência do fato da velocidade da luz ser finita. Por fim, ainda segundo Kawalec (2012), abordar elementos dos telefones celulares em sala de aula seria uma atividade interessante por possibilitar relações com o contexto da vida real.

Neste trabalho, portanto, assumindo a relevância em discutir no ensino de física os limites e possibilidades da Ciência e da Tecnologia e as inter-relações e interinfluências que as mesmas estabelecem com a Sociedade, justifico a proposição de uma sequência de ensino que visa discutir aspectos associados a um artefato tecnológico. Além disso, justifico a opção pelo telefone ao considerar sua forte presença e influência no atual contexto sociocultural. A fim de ilustrar esse fato, apresento a seguir resultados divulgados por duas reportagens relativamente recentes. Segundo reportagem publicada em abril de 2012 pela Revista Exame (Editora Abril) ${ }^{1}$, dados da Agência Nacional de Telecomunicações (ANATEL) indicaram que havia no Brasil no início de 2012

\footnotetext{
1 <http://exame.abril.com.br/tecnologia/noticias/avanco-dos-celulares-leva-telefones-fixos-ao-declinio>.
} Acesso em: 24 ago. 2013.

R. B. E. C. T., vol 6, núm. 3, set-dez.2013 ISSN - 1982-873X 
cerca de 30 milhões de linhas de telefonia fixa. Já segundo reportagem publicada em abril de 2013 pela agência de notícias G1 (Rede Globo) ${ }^{1}$, dados da ANATEL referentes ao início de 2013 indicaram que havia no Brasil cerca de 264 milhões de linhas ativas de telefonia celular, ou seja, cerca de 133 linhas de telefonia móvel para cada 100 habitantes.

Dito isto, vale explicitar como a sequência de ensino proposta está organizada. Numa primeira parte, procuro discutir um pouco acerca da história e dos antecedentes do telefone. Já na segunda e na terceira parte, visando contribuir para a compreensão do funcionamento desse artefato tecnológico, apresento, respectivamente, conceitos físicos a ele associados e um experimento relativamente simples.

\section{0 telefone: um pouco de história}

Desde a antiguidade os povos se preocupam em se comunicar de maneira mais ágil e eficiente - dentro das possibilidades conhecidas em cada época.

Talvez, juntamente com a internet, o maior representante contemporâneo dessa realidade seja o telefone moderno, o qual é produto da contribuição de diversos pesquisadores, diversas mentes trabalhando em paralelo ao longo da história. Ou seja, diferentemente do que costumamos pensar, as invenções e inovações não são eventos pontuais, pois muitas vezes surgem a partir de um processo de maturação de ideias e de um esforço coletivo que busca proporcionar determinado avanço em relação ao que se tem à época.

Embora o processo de desenvolvimento científico e tecnológico seja sempre coletivo, costumeiramente apenas o pesquisador que dá a última contribuição para o desenvolvimento leva o título de "inventor" - fato que também ocorreu no caso da criação do telefone.

Até hoje, entretanto, há uma enorme discussão sobre quem, de fato, deu o passo derradeiro para a construção do primeiro telefone, pois, embora o escocês Alexander Graham Bell tenha sido o primeiro a patenteá-lo e, por isso, costumeiramente leve o crédito pela invenção, em 2002, nos EUA, foi reconhecido oficialmente que o italiano Antonio Meucci já o havia criado ${ }^{2}$. O estadunidense Elisha Gray é outro pesquisador muitas vezes lembrado quando o assunto é a criação do telefone.

\footnotetext{
1 <http://g1.globo.com/tecnologia/noticia/2013/04/brasil-chega-264-mi-de-linhas-de-telefonia-movel-emmarco.html>. Acesso em: 24 ago. 2013.

${ }^{2}$ Uma reportagem com o título um tanto quanto irônico de "Bell did not invent telephone, US rules" do jornal britânico "The Guardian" comenta o caso. Disponível em: <http://www.guardian.co.uk/world/2002/jun/17/humanities.internationaleducationnews>. Acesso em: 24 ago. 2013.
} 
No que diz respeito a artefatos similares ao telefone, poderíamos identificar o telégrafo, criado no fim do século XVIII, como o de maior destaque.

O telégrafo permitia a transmissão de mensagens escritas à distância. Para isso, era utilizado o famoso sistema de signos "código Morse", o qual permitia enviar e depois "decifrar" as mensagens, ou seja, interpretar, o que as linhas traçadas pelo telégrafo significavam. O sistema era usado principalmente por grandes companhias, homens de negócios e pessoas ricas que sabiam operar a máquina e tinham conhecimento do código. Porém, havia algumas características passíveis de melhora no telégrafo, como, por exemplo, o fato das conversas não serem instantâneas, isto é, levava certo tempo para decifrar as mensagens. Mesmo assim, ele obteve considerável e rápido sucesso devido, em boa parte, a aperfeiçoamentos realizados por diversos cientistas (SANGER, 2005; IF-UFRGS, s/d).

Quase um século depois da criação do telégrafo, isto é, já na segunda metade do século XIX, após muitos estudos e pesquisas, surge o telefone. Seu funcionamento pode ser sintetizado da seguinte maneira: primeiramente, as ondas sonoras da voz humana são captadas por uma membrana e convertidas em sinais elétricos. Na sequência, esses sinais elétricos são conduzidos por fios até chegarem a seu destino, onde são agora convertidos em ondas sonoras, podendo-se, assim, ouvir a mensagem transmitida (MENEZES, 2005; PAVATE, 2000).

Obviamente, não é tão simples quanto a breve descrição acima pode sugerir. Um dos problemas que tiveram que ser enfrentados, por exemplo, foi o da qualidade do sinal elétrico transmitido, o qual era, inicialmente, pouco intenso. Thomas Edison - personagem bastante conhecido como o criador da lâmpada - resolveu esse problema substituindo a membrana por um disco de carvão comprimido por duas placas metálicas. Dessa forma, a intensidade dos sinais elétricos gerados pôde ser aumentada, o que elevou a qualidade do equipamento e contribuiu para seu sucesso comercial. Vale ressaltar ainda, que os microfones de carbono que compunham os telefones só foram substituídos por microfones elétricos por volta dos anos 80 do século XX (FRANKLIN INSTITUTE, s/d).

\section{0 telefone: um pouco de física}

Para compreender de maneira mais detalhada o funcionamento do telefone é necessário compreender algumas características dos sons e das correntes elétricas.

O som pode ser definido como a percepção auditiva de ondas sonoras, as quais são classificadas como ondas mecânicas longitudinais. Mecânicas porque precisam de um meio material para se propagar (diferentemente das ondas eletromagnéticas - luz - que se propagam também no vácuo). Longitudinais porque a direção de propagação das ondas coincide com a direção de vibração das partículas do meio material. Um objeto vibrante, como a membrana de um alto-falante, por exemplo, através de seu movimento repetitivo para frente e para trás gera 
regiões de compressão e rarefação (variação de pressão) que se propagam como uma onda sonora. Cada movimento de "vai e vem" constitui uma oscilação. A frequência (f) de uma onda é definida, então, como o número de oscilações por unidade de tempo. Já o período (T) é definido como o intervalo de tempo de uma oscilação completa. A altura do som, isto é, se ele é mais grave ou agudo, é determinada pela frequência da onda sonora: quanto maior a frequência, mais agudo é o som. E, embora possa variar de uma pessoa para outra e com a idade, sabe-se que o ouvido humano pode captar ondas sonoras com frequências entre cerca de $20 \mathrm{~Hz}$ e $20.000 \mathrm{~Hz}$. A característica do som coloquialmente conhecida como "volume" está associada à quantidade de energia transportada pela onda, a qual, por sua vez, é proporcional ao quadrado da amplitude da onda. Vale frisar ainda, que ao se propagar, o som perde intensidade por se espalhar para todos os lados. Há, contudo, uma forma de minimizar essa perda: fazer com que o som se propague dentro de determinado material, num tubo, por exemplo. Por fim, quanto à velocidade, apesar de rápidas, as ondas sonoras estão longe de serem instantâneas. No ar, a velocidade delas varia entre cerca de 330 a 360 metros por segundo, dependendo da temperatura e da umidade do ar. Já na água, a velocidade do som é bem maior, em torno de 1.500 metros por segundo (HALLIDAY, RESNICK e WALKER, 2002; TIPLER, 1978; NUSSENZVEIG, 1997).

Após essa breve caracterização do som, vale também discutir alguns elementos de eletricidade.

A corrente elétrica (i) é uma grandeza física que pode ser caracterizada de maneira simplificada como cargas elétricas em movimento ordenado. De maneira mais formal, $\mathrm{i}=\mathrm{dq} / \mathrm{dt}$, onde dq é a quantidade de carga que atravessa a seção transversal de um condutor em um intervalo de tempo dt. Outra propriedade elétrica importante é a resistência elétrica entre dois pontos quaisquer de um condutor ( $R$ ), a qual é determinada aplicando-se uma diferença de potencial $(V)$ entre esses pontos e medindo a corrente elétrica resultante. Assim: $R=V / i$, ou seja, a resistência elétrica é inversamente proporcional à corrente elétrica: quanto maior a resistência elétrica menor a corrente elétrica para uma dada diferença de potencial. Uma propriedade similar à resistência elétrica, mas que diz respeito a materiais e não a objetos, é a resistividade elétrica $(\rho)$, que é o inverso da condutividade elétrica $(\sigma): \rho=1 / \sigma$. Vale mencionar ainda que, pela Lei de Ampère, um condutor percorrido por corrente elétrica gera ao seu redor um campo magnético (HALLIDAY, RESNICK e WALKER, 2002; TIPLER, 1978; NUSSENZVEIG, 1997).

Pensando em termos do microfone introduzido por Thomas Edison (um disco de carvão comprimido por duas placas metálicas), o funcionamento do telefone pode ser explicado simplificadamente da seguinte maneira: aplica-se uma diferença de potencial (V) ao microfone; quando as ondas sonoras atingem a placa metálica, comprimem o disco de carvão; como o carvão é constituído por carbono - cuja resistência elétrica é bastante sensível a variações de pressão (como as causadas por ondas sonoras), a corrente elétrica que passará pelo circuito irá variar na mesma frequência da onda sonora incidente, transportando, portanto, essa informação. Esses 
sinais elétricos são conduzidos por fios elétricos até chegarem a seu destino - o alto-falante -, onde sofrem agora o processo inverso, isto é, são convertidos de volta a ondas sonoras. $\mathrm{O}$ altofalante é composto, basicamente, por um ímã permanente, uma bobina elétrica (fio condutor enrolado em forma de espiral) colocada no interior do campo magnético gerado pelo ímã e uma membrana anexada à bobina. Quando a corrente elétrica gerada pelo microfone percorre a bobina do alto-falante, o campo magnético por ela produzido interage com o campo magnético gerado pelo ímã permanente, resultando em forças de atração e repulsão que fazem a membrana se movimentar, produzindo, assim, variações de pressão no ambiente, ou seja, ondas sonoras.

Interessante notar que o desenvolvimento do telefone enquanto artefato tecnológico não se reduz a uma aplicação de princípios científicos. Nesse sentido, a criação do telefone (década de 70 do século XIX) ocorreu muito após a formulação de princípios físicos como a Lei de Ampère (década de 30 do século XIX), não sendo coerente, portanto, acreditar na ideia de que o surgimento do telefone foi uma simples e direta consequência do desenvolvimento da ciência. Pensando as relações entre ciência e tecnologia a partir de um viés interacionista (conforme caracterização de Gardner, 1999), podemos afirmar ainda que a ciência, enquanto atividade humana, também foi beneficiada com o desenvolvimento do telefone, afinal, entre outras coisas, ele possibilitou formas mais ágeis de comunicação entre pesquisadores.

\section{0 telefone: um experimento}

Visando ilustrar o funcionamento do telefone, bem como contribuir para sua compreensão, sugiro agora um experimento de simples realização - o qual, segundo alguns relatos históricos, também teria sido realizado por Bell com materiais similares.

Os materiais necessários são: um diapasão de garfo, uma bateria de nove Volts (V), um alto-falante, três pedaços de fios elétricos e um recipiente com água e vinagre (a função do vinagre é deixar a água mais ácida, aumentando sua condutividade elétrica). O diapasão de garfo pode ser encontrado em lojas de instrumentos musicais, a bateria pode ser encontrada facilmente em qualquer supermercado, o alto-falante pode ser retirado de "caixinhas" de som de computadores ou de telefones velhos e os fios elétricos podem ser encontrados facilmente em lojas de equipamentos elétricos ou junto a eletricistas.

O único material que talvez seja relativamente desconhecido entre os estudantes é o diapasão (muitas vezes chamado de diapasão de garfo - pois já existem “diapasões digitais"). Seu uso se dá principalmente na afinação de instrumentos musicais. Em suma, trata-se de um metal em forma de "U" que ao ser batido contra outra superfície passa a vibrar emitindo som de determinada frequência (a frequência depende do comprimento das duas partes que o formam e do material de que é feito) - lembrando que qualquer som é gerado por meio de vibrações. 
A figura 1 mostra o esquema visual do experimento. Já a Figura 2 mostra uma foto da montagem experimental:

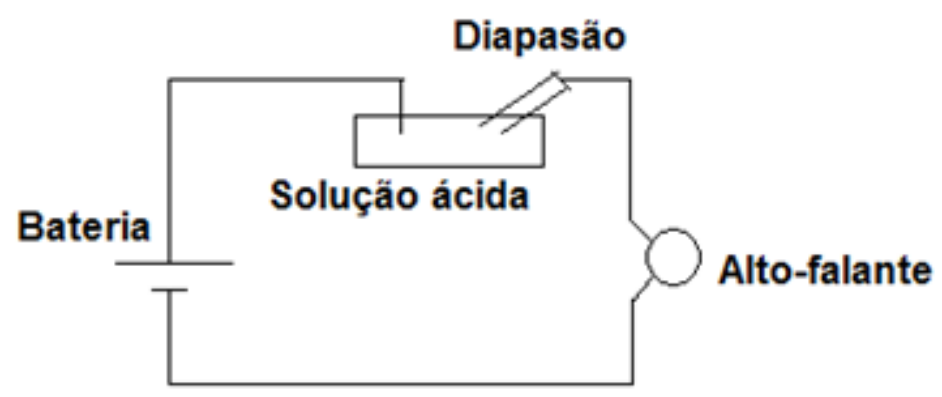

Figura 1: Esquema experimental

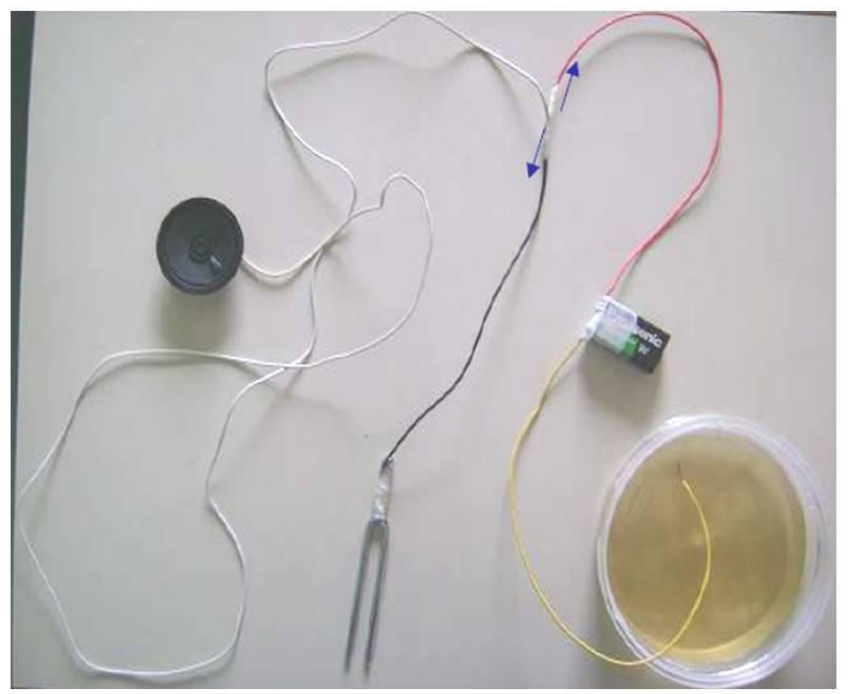

Figura 2: Montagem experimental

Como é possível notar a partir das Figuras 1 e 2, um fio elétrico (o amarelo) é conectado a um dos polos da bateria e deixado dentro da solução ácida; outro fio elétrico (o vermelho) é conectado ao outro polo da bateria e a um dos fios elétricos provenientes do alto-falante; finalmente, o terceiro fio elétrico (o preto) é conectado ao outro fio proveniente do alto-falante e ao diapasão.

O experimento funciona da seguinte maneira: aproximamos o diapasão (já vibrando) o mais paralelamente possível da solução ácida (condutora de eletricidade), de forma que ele apenas toque levemente a superfície, "fechando", assim, o circuito elétrico. Ao fazer isso, a profundidade do diapasão no líquido varia, fazendo com que a resistência elétrica (ou seja, a capacidade de se opor à passagem de corrente elétrica) entre ele e a solução e, 
consequentemente, a resistência elétrica do circuito, também varie, o que, por sua vez, faz com que a corrente elétrica através do circuito flutue na mesma frequência do diapasão. Finalmente, é possível ouvir o som do diapasão através do alto-falante porque este desempenha a função de transformar essa corrente elétrica em som.

Observações em relação à montagem e ao funcionamento do experimento:

a) É indiferente o polo da bateria (positivo ou negativo) que será ligado ao alto-falante;

b) Deve-se colocar o alto-falante próximo ao ouvido a fim de perceber nitidamente o som do diapasão;

c) O fio que sai de um dos polos da bateria deve ser deixado dentro da solução ácida caso o recipiente não seja metálico;

d) Deve-se colocar o diapasão (já vibrando) o mais paralelamente possível da solução ácida, fazendo, porém, com que apenas um dos lados do garfo, isto é, uma das metades do " $U$ ", toque levemente a superfície do líquido. Se colocá-lo perpendicularmente à superfície da solução (como um " $\mathrm{U}$ " invertido), ou com as duas partes do garfo tocando o líquido (ou seja, com o diapasão todo paralelo à superfície da solução) provavelmente o som não será ouvido;

e) Não se deve afundar muito o diapasão na solução, pois dessa forma, as vibrações dele são amortecidas e o som cessa muito rapidamente;

f) Não há diferença em termos da montagem do circuito entre os dois fios que compõem o alto-falante;

g) Ao invés de água com vinagre podemos usar somente água, porém, o som do diapasão será ouvido numa intensidade menor;

h) $\mathrm{O}$ experimento pode ser realizado também com uma pilha de 1,5 V ao invés da bateria de nove Volts, porém, o sinal obtido se tornará mais fraco, afinal, a intensidade da corrente diminuirá.

\section{Considerações finais}

Neste trabalho, diferentemente de boa parte dos trabalhos selecionados a partir da revisão de literatura realizada, a sequência de ensino apresentada é explicitamente direcionada para o ensino de ciências, mais especificamente, para o ensino de física no nível médio. Nesse sentido, creio que a proposta aqui sugerida possa contribuir para a discussão de conceitos associados a ondas sonoras e à eletricidade; para a discussão das inter-relações entre ciência e tecnologia e para a discussão de aspectos relacionados à natureza dos trabalhos científico e tecnológico. 
A sequência de ensino proposta abre também as possibilidades de discutir aspectos associados à telefonia móvel e ao impacto sócio-cultural da utilização de novos artefatos tecnológicos. Nesse sentido, Pampanelli (2004), amparada em pensadores da chamada Escola de Toronto de Teoria da Comunicação, afirma que a história do desenvolvimento do telefone, ao interferir em nossas noções de tempo e distância, reflete em diferentes sentidos culturais, práticas sociais e sociabilidades. A autora evidencia ainda como o telefone está se mostrando capaz de englobar cada vez mais outros meios, tais como mensagens de texto, rádio e internet. Por fim, Pampanelli (2004) afirma ainda que:

"A partir do desenvolvimento e a disseminação das tecnologias de comunicação, o indivíduo passou a experimentar duas formas de interagir com o conhecimento e com outras pessoas: uma física, concreta e outra virtual, imaterial. As tecnologias de comunicação ampliaram e acentuaram as capacidades humanas de falar, ouvir e ver. Estas experiências aprimoradas pelo surgimento de artefatos técnicos ao longo do tempo fizeram com que o homem pudesse criar mecanismos diferentes para se comunicar cada vez mais. $[\ldots] s / p . "$

Finalmente, creio que a sequência de ensino proposta neste trabalho abra ainda outra possibilidade: a de problematizar a tecnologia (possibilidade coerente com o enfoque CTS). Dessa forma, adotando uma postura mais cautelosa, mais realista, pode-se evidenciar o fato de que o desenvolvimento de novos e cada vez mais modernos artefatos tecnológicos não implica necessariamente em progresso, em desenvolvimento humano, enfim, em efeitos que podem ser considerados positivos. Há sempre interesses em jogo. Logo, se por um lado o desenvolvimento de determinado artefato tecnológico pode propiciar maior conforto, facilidade ou até mesmo um auxílio mais eficiente no diagnóstico de problemas de saúde, por outro lado, ele também pode alimentar o chamado "consumismo" ${ }^{1}$, favorecer o consumo insustentável de recursos naturais e acentuar os efeitos das desigualdades socioeconômicas. Nesse sentido, pode-se dizer que apenas as classes economicamente mais favorecidas têm acesso aos mais modernos artefatos tecnológicos, pois, em nossa sociedade, o acesso a esses produtos se massifica apenas quando eles já não são os mais modernos existentes.

\footnotetext{
1 Embora possa assumir diversas caracterizações, o termo "consumismo" costuma designar a aquisição frívola de bens. (VASCONCELLOS-SILVA et al., 2010).
} 


\section{Referências}

ABDUL-RAZZAK, W.; BUSHEY, R.; WINN, G. Leakage of microwave ovens. Physics Education, v. 46, n. 4, p. 417-420, 2011. Disponível em: <http://iopscience.iop.org/0031-9120/46/4/007>. Acesso em: 28 ago. 2013.

ANDREWS, C.; SIMMONS, A.; WILLIAMS, S. Magnetic resonance imaging and spectroscopy. Physics Education, v. 31, n. 2, p. 80-85, 1996. Disponível em: <http://iopscience.iop.org/00319120/31/2/015?fromSearchPage=true>. Acesso em: 28 ago. 2013.

ANDREWS, D. G. H. An experiment to demonstrate the principles and processes involved in medical Doppler ultrasound. Physics Education, v. 35, n. 5, p. 350-353, 2000. Disponível em: <http://iopscience.iop.org/0031-9120/35/5/307>. Acesso em: 28 ago. 2013.

ANGOTTI, J. A.; BASTOS, F. P.; MION, R. A. Educação em física: discutindo ciência, tecnologia e sociedade. Ciência \& Educação, v. 7, n. 2, p.183-197, 2001. Disponível em:

<http://www.scielo.br/pdf/ciedu/v7n2/04.pdf>. Acesso em: 29 ago. 2013.

ANGOTTI, J. A. P.; MION, R. A. Equipamentos geradores e a formação de professores de física. In: Angotti, J. A. P.; Rezende Junior, M. F. (Org.). Prática de ensino de física. Florianópolis: Educar para Vencer, p. 91-116, 2001.

BABICHAK, C. C. Laser. Ciência \& Ensino, n. 5, p. 24-27, 1998. Disponível em: $<$ http://prc.ifsp.edu.br/ojs/index.php/cienciaeensino/article/view/47/48>. Acesso em: 28 ago. 2013.

BAGNATO, V. S. Os fundamentos da luz laser. A Física na Escola, v. 2, n. 2, p. 4-9. 2001. Disponível em: <http://www.sbfisica.org.br/fne/Vol2/Num2/a02.pdf>. Acesso em: 28 ago. 2013.

BALL, J. E. Liquid crystals. Physics Education, v. 15, n. 2, p. 108-109, 1980. Disponível em: <http://iopscience.iop.org/0031-9120/15/2/010>. Acesso em: 28 ago. 2013.

BARAM-TSABARI, A.; YARDEN, A. Characterizing children's spontaneous interests in science and technology. International Journal of Science Education, v. 27, n. 7, p. 803-826, 2005. Disponível em: <http://www.tandfonline.com/doi/full/10.1080/09500690500038389>. Acesso em: 28 ago. 2013.

BARKER, M. C. J. Medical imaging. Physics Education, v. 31, n. 2, p. 70-75, 1996. Disponível em: <http://iopscience.iop.org/0031-9120/31/2/013?fromSearchPage=true>. Acesso em: 28 ago. 2013.

BILANIUK, L. T.; BILANIUK, O. M. NMR imaging in medicine. Physics Education, v. 19, n. 5, p. 247252, 1984. Disponível em: <http://iopscience.iop.org/00319120/19/5/005?fromSearchPage=true>. Acesso em: 28 ago. 2013. 
BRADSHAW, M. J. Liquid crystal devices. Physics Education, v. 18, n. 1, p. 20-26, 1983. Disponível em: <http://iopscience.iop.org/0031-9120/18/1/309>. Acesso em: 28 ago. 2013.

BRASIL, Secretaria de Educação Básica. Parâmetros Curriculares Nacionais para o Ensino Médio (PCNEM). Brasília: Ministério da Educação, 1997.

BRYANT, T. H. E. New techniques in diagnostic radiology. Physics Education, v. 13, n. 2, p. 88-91, 1978. Disponível em: <http://iopscience.iop.org/0031-9120/13/2/004>. Acesso em: 28 ago. 2013.

CAMMARATA, F.; WAUTELET, M. Medical lasers and laser-tissue interactions. Physics Education, v. 34, n. 3, p. 256-161, 1999. Disponível em: <http://iopscience.iop.org/0031-9120/34/3/313>. Acesso em: 28 ago. 2013.

CATELLI, F.; VILLAS-BOAS, V. Exploração de alguns conceitos do eletromagnetismo no movimento do braço de um disco rígido. Caderno Brasileiro de Ensino de Física, v. 28, n. 2, p. 476-489, 2011. Disponível em: <http://www.periodicos.ufsc.br/index.php/fisica/article/view/21757941.2011v28n2p476/19036>. Acesso em: 28 ago. 2013.

CAVALCANTE, M. A.; PEÇANHA, R.; LEITE, V. F. Princípios básicos de imagens ultra-sônicas e a determinação da velocidade do som no ar através do eco. A Física na Escola, v. 12, n. 2, p. 6-11, 2011. Disponível em: <http://www.sbfisica.org.br/fne/Vol12/Num2/a03.pdf>. Acesso em: 28 ago. 2013.

CAVALCANTE, M. A.; PEÇANHA, R.; LEITE, V. F. Princípios básicos de imagens ultra-sônicas e a determinação da velocidade do som no ar através do eco. A Física na Escola, v. 13, n. 1, p. 19-23, 2012. Disponível em: <http://www.sbfisica.org.br/fne/Vol13/Num1/a07.pdf>. Acesso em: 28 ago. 2013.

CHRISTIDOU, V. Greek Students' Science-related Interests and Experiences: Gender differences and correlations. International Journal of Science Education, v. 28, n. 10, p. 1181-1199, 2006. Disponível em:

<http://www.tandfonline.com/doi/full/10.1080/09500690500439389\#tabModule>. Acesso em: 28 ago. 2013.

COSTA, I. F. Pense e responda! Qual o comprimento e a profundidade de bits em CD, DVD e BD? Caderno Brasileiro de Ensino de Física, v. 24, n. 3, p. 333-337, 2007. Disponível em:

<https://periodicos.ufsc.br/index.php/fisica/article/view/6239/13484>. Acesso em: 28 ago. 2013. CRAWFORD, G. P.; ONDRIS-CRAWFORD, R. J. Liquid crystal displays: molecules at work. Physics Education, v. 29, n. 5, p. 307-312, 1994. Disponível em: <http://iopscience.iop.org/00319120/29/5/008 >. Acesso em: 28 ago. 2013.

CUPANI, A. A tecnologia como problema filosófico: três enfoques. Scientiae Studia, v. 2, n. 4, p. 493-518, 2004. Disponível em: 
<http://www.ifcs.ufrj.br/ cehc/Artigos/alberto\%20cupani/atecnologiacomoproblemafilosofico.pd f>. Acesso em: 28 ago. 2013.

DAMASIO, F.; CALLONI, G. Plasma: dos antigos gregos à televisão que você quer ver. A Física na Escola, v. 9, n. 1, p. 15-19, 2008. Disponível em:

<http://www.periodicos.ufsc.br/index.php/fisica/article/view/6239/13484>. Acesso em: 28 ago. 2013.

DAUMAS, M. The history of technology: its aims, its limits, its methods. In: A. R. Hall and N. Smith (ed.), History of Technology, v. 1, London: Mansell, p. 89-112, 1976.

DIAS, A. C. G.; BARLETTE, V. E.; MARTINS, C. A. G. A opinião de alunos sobre as aulas de eletricidade: uma reflexão sobre fatores intervenientes na aprendizagem. Experiências em Ensino de Ciências, v. 4, n. 1, p. 107-117, 2009. Disponível em:

<http://if.ufmt.br/eenci/artigos/Artigo_ID76/v4_n1_a2009.pdf>. Acesso em: 28 ago. 2013.

ELLINGTON, H. I.; ADDINALL, E.; HATELY, M. C. The physics of television broadcasting. Physics Education, v. 15, p. 222-228, 1980. Disponível em: <http://iopscience.iop.org/00319120/15/4/005?fromSearchPage=true $>$. Acesso em: 28 ago. 2013.

ERICSON, T. J. Nuclear magnetic resonance apparatus at low cost. Physics Education, v. 7, n. 2, p. 107-111, 1972. Disponível em: <http://iopscience.iop.org/0031-9120/7/2/006>. Acesso em: 28 ago. 2013.

FIRME, R. N.; AMARAL, E. M. R. Concepções de professores de química sobre ciência, tecnologia, sociedade e suas inter-relações: um estudo preliminar para o desenvolvimento de abordagens CTS em sala de aula. Ciência \& Educação, v. 14, n. 2, p. 251-269, 2008. Disponível em: <http://www.scielo.br/pdf/ciedu/v14n2/a05v14n2.pdf>. Acesso em 29 ago. 2013.

FOX, R. Probing the body with Doppler ultrasound. Physics Education, v. 31, n. 2, p. 85-90, 1996. Disponível em: <http://iopscience.iop.org/0031-9120/31/2/016>. Acesso em: 28 ago. 2013.

FRANKLIN INSTITUTE. Telephone Transmitter, s/d. Disponível em <http://www.fi.edu/learn/casefiles/edison/telephone.html>. Acesso em 11/02/13.

FREEMAN, K. G. The physics of colour television. Physics Education, v. 5, n. 6, p. 326-331, 1970. Disponível em: <http://iopscience.iop.org/0031-9120/5/6/302>. Acesso em: 28 ago. 2013. FRENCH, M. M. J. A mobile phone Faraday cage. Physics Education, v. 46, n. 3, p. 290-293, 2011. Disponível em: <http://iopscience.iop.org/0031-9120/46/3/005>. Acesso em: 28 ago. 2013.

GARDNER, P. L. The representation of science-technology relationships in Canadian physics textbooks. International Journal of Science Education, v. 21, n. 3, p. 329-347, 1999. Disponível em: <http://www.tandfonline.com/doi/abs/10.1080/095006999290732>. Acesso em: 28 ago. 2013.

R. B. E. C. T., vol 6, núm. 3, set-dez.2013 ISSN - 1982-873X 
GOSLING, R. Medical imaging with ultrasound: some basic physics. Physics Education, v. 24, n. 4, p. 215-221, 1989. Disponível em: <http://iopscience.iop.org/0031-9120/24/4/310>. Acesso em: 28 ago. 2013.

GRANGER, G. G. A ciência e as ciências. Tradução de Roberto Leal Ferreira. São Paulo: Editora da Universidade Estadual Paulista (Unesp), 1994.

HALLIDAY, D.; RESNICK, R.; WALKER, J. Fundamentos de Física, v. 3, 6ạ edição. Rio de Janeiro: Livros Técnicos e Científicos Editora, 2002.

HARE, J. A simple demonstration for exploring the radio waves generated by a mobile phone. Physics Education, v. 45, n. 5, p. 481-486, 2010. Disponível em: <http://iopscience.iop.org/00319120/45/5/004>. Acesso em: 28 ago. 2013.

HEAVENS, O. S. Lasers. Physics Education, v. 3, n. 4, p. 169-176, 1968. Disponível em: <http://iopscience.iop.org/0031-9120/3/4/001>. Acesso em: 28 ago. 2013.

HESSENBRUCH, A. X-rays for medical use. Physics Education, v. 30, n. 6, p. 347-355, 1995. Disponível em: <http://iopscience.iop.org/0031-9120/30/6/006>. Acesso em: 28 ago. 2013. HILL, C. R. Ultrasonic Imaging. Physics Education, v. 13, n. 2, p. 97-101, 1978. Disponível em: <http://iopscience.iop.org/0031-9120/13/2/006>. Acesso em: 28 ago. 2013.

HILL, P. D. Lasers in medicine. Physics Education, v. 24, n. 4, p. 211-214, 1989. Disponível em: <http://iopscience.iop.org/0031-9120/24/4/309>. Acesso em: 28 ago. 2013.

HUGHES, S. Medical ultrasound imaging. Physics Education, v. 36, n. 6, p. 468-475, 2001.

Disponível em: <http://iopscience.iop.org/0031-9120/36/6/304>. Acesso em: 28 ago. 2013.

IF-UFRGS. O Telégrafo, s/d. Disponível em <http://www.if.ufrgs.br/fis/EMVirtual/crono/morse.html> Acesso em 24 ago. 2013.

KAWALEC, T. Should we bother with the speed of light in everyday life? A closer look at GSM technology. Physics Education, v. 47, n. 5, p. 579-583, 2012. Disponível em: <http://iopscience.iop.org/0031-9120/47/5/579>. Acesso em: 28 ago. 2013.

KEEVIL, S. F. Magnetic resonance imaging in medicine. Physics Education, v. 36, n. 6, p. 476-485, 2001. Disponível em: <http://iopscience.iop.org/0031-9120/36/6/305?fromSearchPage=true>. Acesso em: 28 ago. 2013.

LABURÚ, C. E.; SIMÕE, A. M.; URBANO, A. A. Mexendo com polaróides e mostradores de cristais líquidos (O ensino da Física contemporânea, tendo como pano de fundo a física do cotidiano). Caderno Catarinense de Ensino de Física, v. 15, n. 2, p. 192-205, 1998. Disponível em: <http://www.periodicos.ufsc.br/index.php/fisica/article/view/6900/6360>. Acesso em: 28 ago. 2013. 
LABURÚ, C. et al. Visualizando ondas eletromagnéticas estacionárias (um experimento na cozinha de casa). Caderno Catarinense de Ensino de Física, v. 17, n. 3, p. 328-335, 2000. Disponível em: <http://www.periodicos.ufsc.br/index.php/fisica/article/view/6764/6232>. Acesso em: 28 ago. 2013.

MENEZES, L. C. De corpo inteiro e viva, a física. A Física na Escola, v. 6, n. 1, p. 27-30, 2005. Disponível em: <http://www.sbfisica.org.br/fne/Vol6/Num1/menezes.pdf>. Acesso em: 28 ago. 2013.

MICHAEL, G. X-ray computed tomography. Physics Education, v. 36, n. 6, p. 442-451, 2001. Disponível em: <http://iopscience.iop.org/0031-9120/36/6/301>. Acesso em: 28 ago. 2013. MION, R. A.; ALVES, J. A. P.; CARVALHO, W. L. P. Implicações da relação entre ciência, tecnologia, sociedade e ambiente: subsídios para a formação de professores de Física. Experiências em Ensino de Ciências, v. 4, n. 2, p. 47-59, 2009. Disponível em: <http://if.ufmt.br/eenci/artigos/Artigo_ID81/v4_n2_a2009.pdf>. Acesso em: 28 ago. 2013. NUSSENZVEIG, H. M. Curso de física básica, v. 3. São Paulo, SP: E. Blucher, 1997.

ORTON, J. W. Physics in an industrial research laboratory. Physics Education, v. 22, n. 1, p. 79-84, 1987. Disponível em: <http://iopscience.iop.org/0031-9120/22/2/002>. Acesso em: 28 ago. 2013. PAMPANELLI, G. A. A Evolução do Telefone e uma Nova Forma de Sociabilidade: o Flash Mob. Razón y Palabra, n. 41, ano 9, 2004. Disponível em: <http://www.razonypalabra.org.mx/anteriores/n41/gazevedo.html>. Acesso em: 31 ago. 2013. PARKER, K.; VOLLMER, M. Bad food and good physics: the development of domestic microwave cookery. Physics Education, v. 39, n. 1, p. 82-90, 2004. Disponível em: <http://iopscience.iop.org/0031-9120/39/1/007?fromSearchPage=true>. Acesso em: 28 ago. 2013.

PAVATE, K. D. Thomas Alva Edison. Resonance, v. 5, n. 1, Springer India in co-publication with Indian Academy of Sciences, Janeiro 2000. Disponível em: <http://link.springer.com/article/10.1007/BF02840370> Acesso em: 29 ago. 2013.

PINHEIRO, N. A. M.; SILVEIRA, R. M. C. F.; BAZZO, W. A. Ciência, tecnologia e sociedade: a relevância do enfoque CTS para o contexto do ensino médio. Ciência \& Educação, v. 13, n. 1, p. 71-84, 2007. Disponível em: <http://www.scielo.br/pdf/ciedu/v13n1/v13n1a05.pdf> Acesso em: 29 ago. 2013.

PODUSKA, E. L.; LUNETTA, V. N. The role of applied physics in American introductory physics courses. Physics Education, v. 19, n. 5, p. 241-246, 1984. Disponível em: <http://iopscience.iop.org/0031-9120/19/5/004?fromSearchPage=true>. Acesso em: 28 ago. 2013. 
PULLAN, B. R. Computerised axial tomography. Physics Education, v. 13, n. 2, p. 92-96, 1978. Disponível em: <http://iopscience.iop.org/0031-9120/13/2/005>. Acesso em: 28 ago. 2013.

SANGER, C. Mobile World: Past Present and Future. Springer London, 2005.

SILVEIRA, R. M. C. S.; BAZZO, W. Ciência, tecnologia e suas relações sociais: a percepção de geradores de tecnologia e suas implicações na educação tecnológica. Ciência \& Educação, v. 15, n. 3, p. 681-694, 2009. Disponível em: <http://www.scielo.br/pdf/ciedu/v15n3/14.pdf>. Acesso em: 29 ago. 2013.

STARRETT, M. J. Resonance and radio. Physics Education, v. 43, n. 5, p. 515-518, 2008. Disponível em: <http://iopscience.iop.org/0031-9120/43/5/008?fromSearchPage=true>. Acesso em: 28 ago. 2013.

STRAULINO, S.; ORLANDO, A. A simple radio receiver aids understanding of wireless communication. Physics Education, v. 47, n. 2, p. 211-219, 2012. Disponível em: <http://iopscience.iop.org/0031-9120/47/2/211?fromSearchPage=true>. Acesso em: 28 ago. 2013.

SUMNER, D. X-rays - risks versus benefits. Physics Education, v. 30, n. 6, p. 338-342, 1995. Disponível em: <http://iopscience.iop.org/0031-9120/30/6/004>. Acesso em: 28 ago. 2013. TIPLER, P. A. Física, v. 2. Rio de Janeiro, RJ: Guanabara Dois, 1978.

UTGES, G.; FERNÁNDEZ, P.; JARDÓN, A. Física y tecnología: una integración posible. Caderno Catarinense de Ensino de Física, v. 13, n. 2, p.108-120, 1996. Disponível em: <https://periodicos.ufsc.br/index.php/fisica/article/view/7052/6528>. Acesso em: 29 ago. 2013. VALADARES, E. C.; MOREIRA, A. M. Ensinando Física moderna no segundo grau: Efeito fotoelétrico, laser e emissão de corpo negro. Caderno Catarinense de Ensino de Física, v. 15, n. 2, p. 121-135, 1998. Disponível em:

<http://www.periodicos.ufsc.br/index.php/fisica/article/view/6896/7584>. Acesso em: 28 ago. 2013.

VASCONCELLOS-SILVA, P. R. et al. As novas tecnologias da informação e o consumismo em saúde. Cadernos de Saúde Pública, v. 26, n. 8, p. 1473-1482, 2010. Disponível em: <http://www.scielo.br/pdf/csp/v26n8/02.pdf>. Acesso em: 28 ago. 2013. VOLLMER, M. Physics of the microwave oven. Physics Education, v. 39, n. 1, p. 74-81, 2004. Disponível em: <http://iopscience.iop.org/0031-9120/39/1/006?fromSearchPage=true>. Acesso em: 28 ago. 2013.

VOLLMER, M.; MÖLLMANN, K-P. High speed and slow motion: the technology of modern high speed cameras. Physics Education, v. 46, n. 2, p. 191-202, 2011. Disponível em: <http://iopscience.iop.org/0031-9120/46/2/007>. Acesso em: 28 ago. 2013. 
VOLLMER, M.; MÖLLMANN, K-P.; KARSTÄDT, D. More experiments with microwave ovens. Physics Education, v. 39, n. 4, p. 346-351, 2004a. Disponível em: <http://iopscience.iop.org/00319120/39/4/003>. Acesso em: 28 ago. 2013.

VOLLMER, M.; MÖLLMANN, K-P.; KARSTÄDT, D. More experiments with microwave ovens. Physics Education, v. 39, n. 6, p. 500-508, 2004b. Disponível em: <http://iopscience.iop.org/00319120/39/6/006>. Acesso em: 28 ago. 2013.

André Coelho da Silva. Professor Temporário do Instituto Federal de Educação, Ciência e Tecnologia do Estado de São Paulo (IFSP), campus Itapetininga. Mestre em Educação pela Faculdade de Educação da Universidade Estadual de Campinas (UNICAMP) - apoio: Fundação de Amparo à Pesquisa do Estado de São Paulo (FAPESP) e Coordenação de Aperfeiçoamento de Pessoal de Nível Superior (CAPES) - e Licenciado em Física pela mesma universidade. Email: andco_8@yahoo.com.br. 